\title{
Tree-hole frogs exploit resonance effects
}

\section{These anurans know a trick or two when it comes to the romantic powers of song.}

A nimal mating calls that exert a comparatively high sound pressure propagate over greater distances and generally have greater attractive power ${ }^{1,2}$. Here we show that calling male Bornean tree-hole frogs (Metaphrynella sundana) actively exploit the acoustic properties of cavities in tree trunks that are partially filled with water and which are primarily used as egg-deposition sites. By tuning their vocalizations to the resonant frequency of the hole, which varies with the amount of water that it contains, these frogs enhance their chances of attracting females.

In a simulated tree-hole experiment, we placed a calling male in an opaque plastic tube that was partially filled with water. The frog's vocalizations were recorded the following night as the water level was slowly reduced (increasing the air column from 50 to $144 \mathrm{~mm}$ ) over a period of $28 \mathrm{~min}$. We measured the change in air-column depth from a graduated cylinder connected to the tube, and later sampled time segments from the recording at regular intervals.
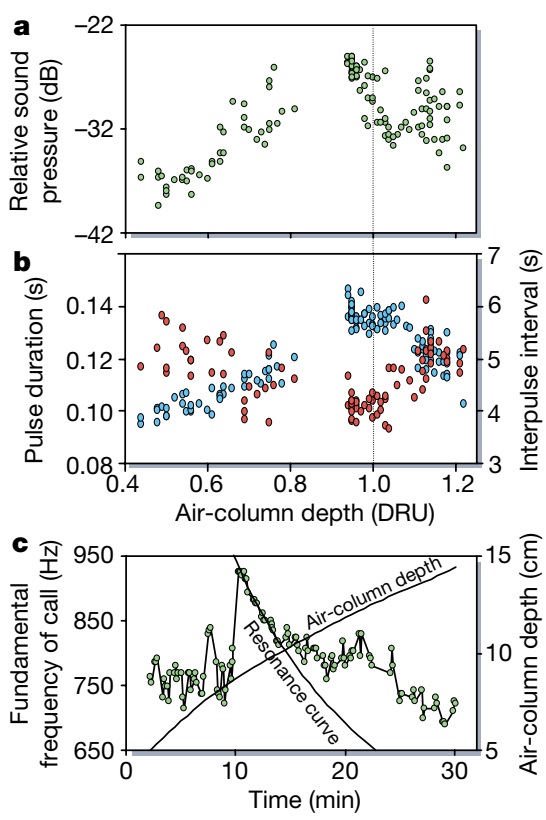

Figure 1 Resonance effect and associated temporal call and pitch alterations of a tree-hole frog calling from inside a tube as the aircolumn depth increases. a, A sound-pressure peak (resonance effect) is apparent at about 0.95 dynamic resonance units (DRU; the deviation from 1 DRU may be the result of experimental error in the levelling of the tube and graduated cylinder). $\mathbf{b}$, At the resonance peak, the frog produced longer call pulses (blue) and the interpulse interval (red) was at a minimum. c, Call pitch variation over time. The resonance curve indicates the pitch values that give rise to resonance effects as the air-column depth increases (adjusted for the occurrence of resonance effects at 0.95 rather than $1.00 \mathrm{DRU})$.
The frog's call is a simple tonal pulse with little or no frequency modulation; the fundamental frequency is the dominant one. We analysed the call's pitch in relation to the air-column depth in dynamic resonance units (DRU), calculated as the call pitch at any point divided by the resonant frequency at that point. Resonance was predicted to occur at 1 DRU (corresponding to an air-column depth of one-quarter of the wavelength of the current pitch).

A peak in sound pressure was evident at about 0.95 DRU (Fig. 1a). The pulse duration peaked when the resonance effect was strongest (Fig. 1b). Inspection of oscillograms indicated that this was not merely due to an echo effect but to the production of longer call pulses (results not shown). Also, the interval between call pulses was shortest when the sound pressure peaked (Fig. 1b). Both of these call alterations are energetically costly ${ }^{3}$ and are known to increase male attractiveness in many amphibians $^{4-6}$.

In addition to its flexibility in calling effort, the frog initially called with a varying pitch until it found the frequency that resulted in maximum amplitude. It then managed to track closely the falling water level in its resonance-matching over a period of several minutes, gradually lowering its pitch by about $115 \mathrm{~Hz}$ (Fig. 1c). The frog then apparently lost track of the optimal call pitch and resumed calling with an erratic pitch. Although this result relates to only one individual, the most likely explanation for this striking pattern is that the frog was actively tracking the resonant frequency of the tube.

Our field recordings of males calling from natural tree holes (Fig. 2) also show this correlation between pulse duration and interpulse interval, and between pulse duration and call pitch variability (Pearson correlation coefficient of $-0.245, n=238$, $P<0.001$; and correlation coefficient of $-0.237, n=237, P<0.001$, respectively; pitch variability is given as pitch coefficient of variance based on $10 \pm 4$ (mean \pm s.d.) consecutive call pulses). This indicates that frogs in natural tree holes also increase their calling effort if they can adjust their call pitch to match the resonant properties of the hole.

Several crickets $^{7-9}$ and burrowing frogs ${ }^{10,11}$ benefit from sound amplification by calling from baffles or burrows. However, to our knowledge this is the first evidence of an animal not only sampling resonance properties ${ }^{12}$ but also facultatively adjusting its call pitch and calling strategy

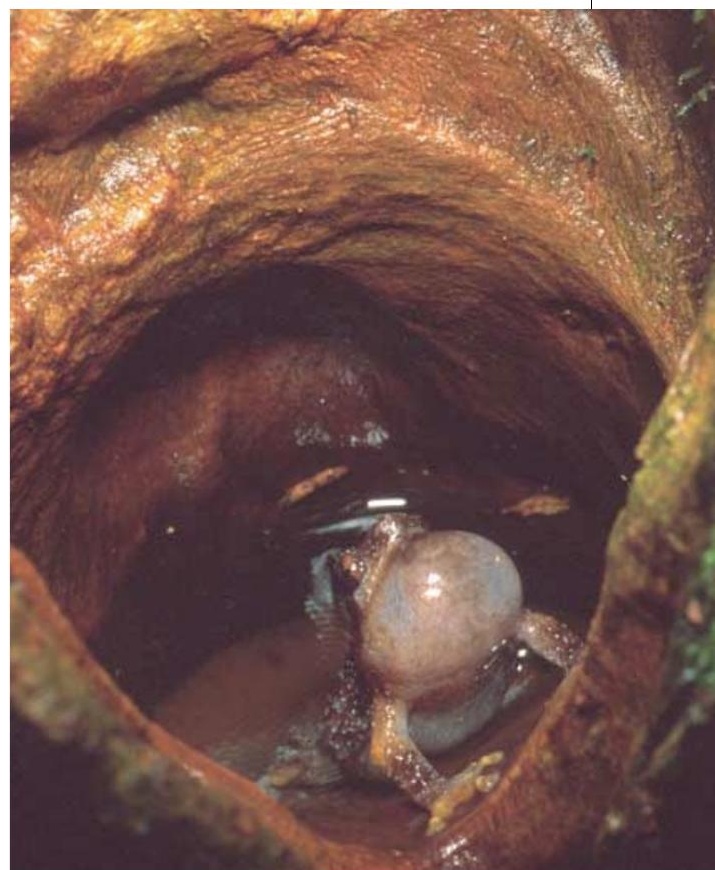

Figure 2 Lover's lair: the tree-hole frog uses acoustic acumen to ensure that his mating calls strike a chord with local females.

in what seems to be an adaptive manner. Our findings indicate that animals may be better at exploiting signal-enhancing structures than was previously appreciated, and that flexibility in related, but not obligately linked, traits may also follow from such adaptive strategies.

Björn Lardner ${ }^{\star}$, Maklarin bin Lakim $\dagger$

${ }^{\star}$ Division of Amphibians and Reptiles,

Field Museum of Natural History, Chicago,

Illinois 60605, USA

e-mail:bjorn.lardner@zooekol.lu.se

$\dagger$ Research and Education Division, Sabah Parks, PO Box 10626, 88806 Kota Kinabalu, Sabah,

Malaysia

1. Gerhardt, H. C., Dyson, M. L. \& Tanner, S. D. Behav. Ecol. 7, 7-18 (1996).

2. Gerhardt, H. C., Tanner, S. D., Corrigan, C. M. \& Walton, H. C. Behav. Ecol. 11, 663-669 (2000).

3. Wells, K. D. in Anuran Communication (ed. Ryan, M. J.) 45-60 (Smithsonian Inst. Press, Washington DC, 2001).

4. Welch, A. M., Semlitsch, R. D. \& Gerhardt, H. C. Science 280, 1928-1930 (1998)

5. Klump, G. M. \& Gerhardt, H. C. Nature 326, 286-288 (1987).

6. Gerhardt, H. C. \& Huber, F. Acoustic Communication in Insects and Anurans (Univ. Chicago Press, Chicago, 2002).

7. Bennet-Clark, H. C. J. Exp. Biol. 128, 383-409 (1987).

8. Bailey, W. J., Bennet-Clark, H. C. \& Fletcher, N. H. J. Exp. Biol. 204, 2827-2841 (2001).

9. Prozesky-Schulze, L., Prozesky, O. P. M., Anderson, F. \& van der Merwe, G. J. J. Nature 255, 142-143 (1975).

10. Bailey, W. J. \& Roberts, J. D. J. Nat. Hist. 15, 693-702 (1981).

11. Penna, M. \& Solis, R. Anim. Behav. 51, 255-263 (1996).

12. Daws, A. G., Bennet-Clark, H. C. \& Fletcher, N. H. Bioacoustics 7, 81-117 (1996)

Competing financial interests: declared none. 